\title{
La influencia del P. Feijoo en América
}

\author{
por Vicente PALACIO ATARD \\ Catedrático de la Univeraidad de Madrid
}

En un escrito que puede fecharse en la séptima década del siglo xviII, y que se publicó en el Semanario Erudito de Valladares a nombre de don Manuel Lanz de Casafonda, ${ }^{1}$ se nos dice que el P. Feijoo "fue venerado por un oráculo en toda España y en las Indias». Nos hallamos ante la celebración del segundo centenario de una figura venerable que dejó honda huella, ciertamente, no sólo en la cultura peninsular española, sino también en la cultura hispanoamericana. Es curioso recordar, al hacer esta afirmación, el desaliento con que el propio Feijoo examina el resultado de su obra algunas veces. "Todos oyen mis voces, y casi todos parece que están sordos a ellas", dice al comenzar a editar sus Cartas Eruditas en 1742. "Quince años ha que estoy declamando contra la fatua credulidad que reina en el mundo, y pienso que el mundo, a reserva de pocos individuos, está como estaba».

Pero el mundo que el P. Feijoo deja al morir, en 1764, no permanece en quietud, no está como estaba en 1725, cuando empezó a escribir.

1. «Del estado presente de la literatura en España, del de las tres Universidades Mayores» de Castilla y de sus Colegio Mayores», Semanario Erudito, t. XXVIII. 
Dentro de las amplias fronteras hispanas, y no sólo en el área peninsular, se había producido un cambio de ritmo, y era un hecho decisivo el examen crítico planteado, imputable en grado no pequeño al Maestro de la Universidad de Oviedo.

Sin embargo, se ha dicho que América significó muy poco en la obra de Feijoo. Esta afirmación sólo es aceptable en el sentido de que, a lo largo de las cinco mil páginas impresas de sus libros, hay muy pocas referencias de tema americano. En un trabajo que publiqué hace algunos años, recogí las principales de estas referencias, y no se trata ahora de volver sobre ellas. Otros autores se han ocupado también de este aspecto. ${ }^{2}$ Pero la relación del P. Feijoo y la cultura americana es doble: cabe preguntarse cómo preocupó al benedictino gallego el mundo americano, su naturaleza, sus habitantes, sus costumbres y vida social. Pero, en segundo término, podemos inquirir acerca del sentido y el alcance del magisterio ejercido por Feijoo sobre la cultura americana de habla española.

América se cruzó como una posibilidad tentadora en la vida del fraile benedictino en un momento bien singular; cuando, más de mediada su vida, se le ofrece, en 1725, un obispado en el Nuevo Mundo. Paradójica coincidencia, porque, al no aceptar la sede episcopal americana y renunciar en ese acto a una carrera eclesiástica brillante, en aquella renuncia estaba contenido todo su futuro, es decir, su carrera de escritor, que entonces se inicia.

El P. Feijoo no ha conocido las tierras de América y sabe poco de las cosas que conciernen a aquel continente, hacia cuyos habitantes -indios o criollos - demuestra, por otra parte, una amplia simpatía; pero gozará de fama imperecedera entre los hombres de letras del mundo americano. Justa fama, sin duda, porque la relación de Feijoo con la cultura americana tiene esa otra valencia, la del magisterio ejercido, aunque él fuera un sedentario y de su Universidad ovetense no salieran discípulos americanos. Pero el alcance y repercusión de la obra de Feijoo ha de medirse por la difusión de sus libros. Creo que se ha calculado en 528.000 el número de ejemplares publicados de los distintos tomos que componen las obras de Feijoo editados en el siglo xviII. Será imposible ave-

2. V. Palacio Atard: «Feijoo y los Americanos», Estudias Americanos, núm. 69-70, Sevilla, 1957. A. Millares Carlo: "Feijoo en América», Cuadernos Americanos, t. III, México, 1944. H. Corbató: "Feijoo y los españoles americanos", Revista Iberoamericana, t. V, Austin (Texas), 1942. A. Tudisco: "America in Feijoo", Hispania. A Teachers' Journal, XXXIX, Baltimore, 1956. Antonello Gerbi alude a la cuestión, centrando el tema en el problema general de las polémicas sobre los habitantes del Nuevo Mundo: La disputa del Nuevo Mundo, historia de una polémica, 1750-1900, traduc. castellana, México, 1960, principalmente en p. 167 y ss. 
riguar, dentro de ese total, el número de ejemplares que pasaron a la América hispana. Mucho más difícil hacernos cabal idea del número, aunque sí de la calidad, de sus posibles lectores. Sin embargo, la influencia de Feijoo en América habrá que rastrearla, ante todo, creo yo, a través de las bibliotecas. Sobre esta pista nos ponía, ya en los mismos días de Feijoo, don José Mariano Gregorio de Elizalde Ita, doctor en Teología y antiguo Rector de la Universidad de México, cuando en el «parecer» que dio sobre la obra del benedictino, incluido en el tomo VI del Teatro Crítico, en 1734, declaraba: "Pues para persuadir el dilatado terreno que hoy ocupa (el $T$. C.) bastará saber que no sólo la Europa toda se deleita con él, sino que, extendiéndose hasta los dilatadísimos términos de la América, en ambos Reinos, y de la Asia en las Filipinas, disfrutan sus individuos al gozar de su hermosura.»

Desde hace algún tiempo, se han hecho prospecciones en los inventarios de las viejas bibliotecas, públicas o privadas, de la época virreinal. La imprenta y la biblioteca señalan las rutas de penetración de la cultura. Investigadores notables, como Torre Revello, el P. Guillermo Furlong, Vicente Cutolo, entre otros, mostraron una vía hacia metas provechosas. Los análisis de las bibliotecas criollas revelan por la cantidad y calidad de los depósitos de libros, un afán de comunicación de ideas y conocimientos entre la élite intelectual americana de habla española. El trabajo de indagación en este sentido sigue completándose cada día con aportaciones interesantes, como la encuesta general realizada por un equipo integrado por Rosa Blanco, Percy Cayo y otros colaboradores en Perú, comunicada en el Seminario de Historia "Riva Agüero»; ${ }^{3}$ o los estudios a escala local tan significativos como el de Jorge Comadrán sobre las bibliotecas cuyanas del siglo XviıI, en el que se analizan más. de veinte colecciones privadas, y cuyo interés se multiplica si consideramos que se refiere a una zona descalificada del gran tráfico literario por su desplazamiento geográfico. ${ }^{4}$

Es más que probable que una parte considerable de las bibliotecas privadas americanas de la segunda mitad del siglo XVIII procedan de los jesuitas expulsos, pues los poseedores de tales colecciones casi siempre

3. La causa de la emancipación del Perú. Testimonios de la época precursora. Actas del simposio organizado por el Seminario de Historia del Instituto Riva-Agüero, Lima, 1960. La comunicación de Rosa Blanco, Percy Cayo, Susana Llontop, Edwin Masseaur y Oscar Zevallos, publicada con el título: Notas para reconstruir una biblioteca del tiempo precursor, en las ps. 209-217.

4. Jorge Comadrán Ruiz: Bibliotecas cuyanas del siglo XVIII. Prólogo de Guillermo Furlong, S. J. Universidad Nacional de Cuyo, Mendoza, 1961. Don Gregorio Marañón comprobó también directamente la amplia difusión de la obra de Feijoo en las bibliotecas de la América de habla española. Véase Dr. Gregorio Liras: El Padre Feijoo en el pensamiento médico de España, Centro de Investigaciones de Historia de la Medicina de la Universidad de Chile, 1959. 
son personalidades más o menos relacionadas con la ejecución de la real orden de extrañamiento de la Compañía, en 1769, y también a veces amigos o protectores de los jesuitas. Los jesuitas coincidieron casi siempre con el padre Feijoo en los propósitos reformadores de la enseñanza y especialmente suelen figurar entre los primeros introductores de la filosofía moderna, es decir, de las nuevas ciencias de la Naturaleza: recordemos el caso del padre Losada y los jesuitas de Salamanca, en la España peninsular, y el de los padres del Colegio de Córdoba del Tucumán, a mediados del siglo xvirI, que fueron reprendidos por sus superiores en razón de sus aficiones innovadoras.

Las bibliotecas de jesuitas daban acogida favorable a la obra de Feijoo, y habrá de suponerse que desde ellas se proyectó ampliamente el cuadro de sus lectores al otro lado del océano. En general, las bibliotecas americanas del siglo xviII contienen inevitablemente el Teatro Crítico y las Cartas Eruditas. Jaime Eyzaguirre Io ha comprobado en Chile. Rosa Blanco y los colaboradores que han trabajado en el estudio sobre las bibliotecas peruanas, hacen esta declaración textual: "Nos ha llamado la atención el lugar preponderante que ocupan en ellas las obras de Feijoo y de Solórzano."

Los «navíos de la Ilustración», como denominara Ramón de Basterra a los de la Real Compañía Guipuzcoana, desembarcaban en Caracas las obras francesas o de cualquier otra procedencia en el siglo xviII. En otros puertos de aquel continente descargaban fardos de libros los correos regulares o los barcos contrabandistas. Pero tengamos presente que los más nutridos e importantes cargamentos de libros procedían de España y eran libros españoles; no todos, ciertamente, de filosofía escolástica, ni de literatura banal, ni de simple piedad o devoción. Los libros de la Ilustración americana son, ante todo, libros españoles. ¿Será exagerado suponer que los ejemplares del Teatro Crítico y de las Cartas Eruditas constituyen el más noble e importante conjunto de aquel cargamento intelectual? Las obras francesas encontraban algún núcleo de lectores en Caracas, en México, en Lima, en Buenos Aires; en los otros parajes de la América hispana eran muy pocos los lectores en condiciones de manejar la lengua francesa. Así nos lo dice, por ejemplo, desde Lima, en 1816, un chileno famoso, fray Camilo Henríquez, cuando se refiere al Chile de 1810: «Escepto como seis de ellos (de los criollos distinguidos), nadie entiende los libros franceses, ninguno los ingleses.»

La influencia directa de Feijoo en la cultura americana hay que situarla en este medio general de lectores a quienes puede llegar la obra de un ensayista distinguido, de un divulgador. Feijoo se propuso ser un 
debelador de errores comunes, y también fue un despertador de aficiones: sobre todo, la gran afición a las ciencias físicas y naturales según las directrices modernas, contra las concepciones escolásticas. Según esto, las influencias feijonianas me parece que se podrán detectar en dos ondas distintas: una onda corta, que se percibe en algunos directos y entusiastas seguidores del benedictino, o en sus contrarios empedernidos, y otra onda larga, de alcance más complejo y difuso en el tiempo, pues si contribuye a provocar una revisión de los estudios y una reelaboración de los conocimientos, tal revisión y reelaboración, cronológicamente distanciados de Feijoo por un lapso de tiempo nada despreciable, no se basa ya exclusivamente en los textos incitadores del fraile gallego, sino también en el estudio directo de otras fuentes de las ciencias y del pensamiento moderno.

Los profesionales aplicados a la observación del hombre y de la naturaleza encontraron en Feijoo estímulos y orientaciones. Fueron sus lectores más fervorosos a veces los médicos, y también fueron sus más enconados contradictores otras, como es bien sabido, por el menosprecio de que hacía gala Feijoo de la profesión médica al uso. En el Chile de la segunda mitad del siglo xviII, pongo por caso, aquel fray Pedro Manuel Chaparro, introductor de la variolación hacia 1765, fue un lector de Feijoo; aunque también superaba las recomendaciones feijonianas por un más alto grado de conocimientos médicos, que le obligaban a rechazar los textos del Dr. Martín Martínez.

Al referirse Marañón a la influencia de Feijoo en las ideas biológicas, pone de manifiesto esas dos ondas a que he hecho alusión: sobre la cultura médica popular y sobre los médicos, de manera directa e inmediata; así las boticas que se cerraron al desacreditar la pluma del fraile benedictino muchos tradicionales remedios, el movimiento renovador de las academias y estudios, más fácil de progresar fuera de las aulas universitarias. En la onda lejana de Feijoo cabe apuntar, junto a la reforma del protomedicato de 1780, los estudios promovidos por Unanue en Lima.

Nuestro P. Feijoo fue dominador de un género literario muy de su siglo: el ensayo. Ligero, vulgarizador, usa de un estilo moderno, diríamos «periodístico». Por eso se le leía con facilidad. En cuanto a su estilo, se le han hecho reproches y ha encontrado reivindicadores. Estoy seguro que en el actual simposio ovetense distinguidos colegas y críticos enriquecerán nuestros conocimientos acerca de este extremo. Tengo para mí que la irregularidad del estilo es propia de Feijoo como de todo aquel que escribe a destajo, con prisas y agobio de tiempo, de que se lamenta en sus cartas. No cabe exigirle una constante pulcritud. Pero sí pueden 
reconocerse como las más excelentes armas intelectuales del estilo literario de Feijoo aquellas que el padre jesuita Antonio Goyeneche subraya en la «aprobación" al último tomo de las Cartas Eruditas: el ingenio, esto es, la habilidad, y la buena fe, lo que equivale a sinceridad; y esas dos armas, añadiría yo, usadas con entusiasmo desbordante, contagioso, persuasivo.

No sé cuáles serán las huellas que el padre Feijoo haya dejado en las letras americanas dentro del campo del ensayo como género literario. Pero si, poniendo de lado los aspectos formales, nos fijamos en el contenido de su pensamiento, vemos decantarse, sin duda, un poso que enriquece la solera antigua, tanto en el ambiente popular culto, como en los niveles selectos de la inteligencia. Dondequiera que existiese un libro de Feijoo, en España o en América, principiaba una acción purificadora, de saneamiento mental.

En los niveles más altos de la inteligencia americana, la influencia abarca, en primer lugar, el arsenal polémico proporcionado para la reivindicación del criollo y su capacidad intelectual, contra las opiniones minusvalizadoras, que eran lugar común en Europa y que encontraban en Buffon, de Pauw y Robertson empeñados sostenedores durante el siglo XvirI. El Lazarillo de ciegos caminantes, de Concolorcorvo, es un testimonio de este tipo de influencias directas, ${ }^{5}$ como lo es también la obra del padre Clavigero.

Otra importante línea de influencias, de mayor hondura y trascendencia para el destino intelectual y la cultura de América, cabe señalarse sobre la actitud polémica de los innovadores americanos que abren paso a la filosofía moderna: en Feijoo encontrarán siempre una autoridad prestigiosa que les facilita argumentos o respalda sus diatribas contra la escolástica: un ejemplo de tales influencias lo encontramos en el sacerdote mexicano del Oratorio, Juan Benito Díaz de Gamarra, filósofo de acreditada fama. ${ }^{6}$ Sin duda, el eco feijoniano en el desenvolvimiento del pensamiento moderno tuvo en América resonancias muy extensas. El padre Feijoo había comprendido todo lo bueno y positivo que traía consigo la ciencia moderna, sin que implicara necesariamente la pérdida de la concepción cristiana del hombre y de la cultura, como denunciaban

5. Antonello Gerbi, op. cit., p. 169, comenta: "Por obra, sobre todo, de Feijoo se iniciaba, pues, un repaso atento de los juicios sobre la degeneración de los criollos, que quizás hubiera llevado a un planteamiento más seguro del problema. Pero sobre esta incipiente revisión calan con fuerza explosiva las teorías buffon-depauwianas, que remachaban con aparente rigor científico la tesis de la ineluctable decadencia de hombres y animales en el Nuevo Mundon.

6. Pablo González Casanova: El misionésmo y la modernidad cristiana en el siglo XVIII México, 1948. 
sus contradictores. Se proponía Feijoo una síntesis de lo más noble de la tradición cultural española y lo mejor de las novedades científicas de la moderna Europa. La ciencia nueva se anunciaba como una ciencia profana, secularizada, lo cual no significaba una necesaria hostilidad al cristianismo. Esto lo entendió muy bien Feijoo, con escándalo de algunos contemporáneos suyos. Y es curioso este escándalo suscitado entre los escolásticos, y hasta resulta paradójico, porque precisamente la escolástica primitiva había dado testimonio en la historia de la incorporación de una ciencia profana, la griega clásica, susceptible de ser asumida en una sabiduría cristiana.

Los resultados del magisterio feijoniano en estos altos niveles de la cultura, como divulgador de las ciencias modernas, los apreciamos en otros dos sectores: en la afición despertada hacia las ciencias experimentales (física, botánica, historia natural) que tuvieron feliz florecimiento en la América española durante la segunda mitad del setecientos, y, además, en el eclecticismo filosófico que caracterizará el pensamiento de entonces en Hispanoamérica.

Feijoo comprendió, mucho antes que otros hombres de su época la absoluta independencia de la investigación en el campo de las ciencias físicas con respecto a la metafísica; y no sólo esto, sino que se anticipó a adoptar una postura ecléctica con respecto al pensamiento de los filósofos modernos, en todo lo que era materia opinable y no artículo de fe. Feijoo sostuvo que las ideas de un hereje o ateo eran susceptibles de un aprovechamiento parcial o fraccionado, por no ser imposible que hubiera en ellas algunas partículas verdaderas, como habían supuesto en casos análogos San Agustín o el propio Santo Tomás. La filosofía cristiana no tendrá reparo en tomar esas partes y articularlas en consonancia con la fe. Semejante actitud no cabe duda que abría nuevos horizontes a la filosofía cristiana del siglo xvII, que no se agota en la escolástica precedente ni en el eclecticismo de aquella centuria. Ahora bien, el eclecticismo americano del setecientos no hubiera encontrado un ambiente propicio en su evolución histórica, si antes no hubieran librado con éxito sus batallas en España los Berní o los Tosca, los Losada o los Feijoo. Gracias a esas batallas previas, quedaron soslayadas muchas dificultades de censura. Por eso, González Casanova dice que el pensamiento de Feijoo influyó en el pensamiento de la modernidad mexicana antes que el procedente de otras mentes de Europa; y merecería la pena una sólida indagación de este supuesto por todo el ámbito americano.?

7. Sobre el eco de las ideas de Feijoo en el pensamiento boliviano, véase G. Francovich: La filosofia en Bolivia, Buenos Aires, 1945. 
En cuanto a las ciencias naturales, bastará recordar los colaboradores americanos que tomaron parte en las expediciones botánicas y naturalistas llevadas a efecto en los dominios americanos de España en la segunda mitad de la centuria decimoctava y en los comienzos del siglo XIX, en especial las de Ruiz y Pavón, las de Sessé y Mociño y los trabajos de José Celestino Mutis. Recordemos, a estos efectos, los elogios tributados a Feijoo por Caldas y por otros naturalistas americanos de su siglo. Pero, sobre todo, es significativo el hecho de que Mutis acudiera a la autoridad de Feijoo para ponerla como escudo cuando pretendían inquietar al sabio botánico desde el ángulo de la ortodoxia.

Hay otra zona de influencias en la cual la sombra benéfica de Feijoo se proyecta sobre la cultura americana, de análogo modo a como acontece en España: me refiero al espíritu que alienta en las reformas universitarias tanteadas durante el reinado de Carlos III y años siguientes. Hace mucho tiempo que Chacón y Calvo señaló influencias feijonianas en las tentativas reformadoras de la Universidad de La Habana. Del mismo modo, cabe contar dentro del círculo de Feijoo las iniciativas de José Baquíjano, de Hipólito Unanue, de Rodríguez de Mendoza, y de Vicente Morales, los «cuatro grandes» del Perú, el frustrado plan de estudios de 1783 en San Marcos, o las directrices del Real Convictorio de San Carlos desde 1785, bajo el rectorado de Rodríguez de Mendoza. En el mismo sentido podríamos considerar la valiosa contribución del padre Liendo de Goicoechea en Guatemala, y el prospecto o "método provisionaln del fiscal criollo Moreno Escandón para los estudios universitarios de Bogotá, en 1779, redactado por encargo del virrey Guirior, del que leo unas líneas que bien pudieran parecer escritas textualmente por el propio P. Feijoo:

«Si en todo el orbe sabio ha sido necesaria la introducción de la filosofía útil, purgando la lógica y metafísica de cuestiones inútiles y reflejas, y sustituyendo a lo que se enseñaba con el nombre de física los sólidos conocimientos de la Naturaleza, apoyados en las observaciones y experiencias, en ninguna parte del mundo parece ser más necesaria que en estos fertilísimos países, cuyo cielo y suelo convidan a reconocer las maravillas del Altísimo, depositadas a tanta distancia de las sabias academias, para ejercitar en algún tiempo la curiosidad de los americanos..18

Sin el reconocimiento de una amplia, efectiva y diversa influencia de Feijoo en América, no se completa la historia de su fama. Fama adqui-

8. Gabriel Porras Troconis: Historia de la cultura en el Nuevo Reino de Granada, Sevilla, 1952, p. 427. 
rida día a día entre sus lectores de aquel continente, al producirse el contraste de opiniones de quienes le admiraban con devoción entusiasta y de quienes a él se opusieron. En América se leían sus obras, como en España, para aprender de él o para oponérsele con encarnizamiento, que es un modo de rendir pleitesía a la inteligencia y reconocer su influjo. El ecuatoriano Santa Cruz y Espejo, en quien abundan las alusiones a Feijoo, al cual leyó con afición, se refiere a esos otros lectores del sabio benedictino que no gustaban de sus opiniones ni poco ni mucho.9 José Ignacio Bartolache, en el Mercurio Volante del 18 de noviembre de 1772, elogia a Feijoo en estos términos: "Yo le venero mucho y gusto muy a mi sabor de todos sus libros, reconociendo cuán merecida y justa es la estimación que nuestra España hace de su mérito.» Idénticas frases elogiosas se encuentran por doquier, en general, en todos aquellos innovadores modernos de la centuria decimoctava a los que consideramos identificados con la actitud mental del benedictino. Sería bien fácil coleccionar una antología de elogios tributados entonces por los hombres de letras americanos, al estilo del panegírico hecho por don Ignacio de Escandón en Lima, en 1765. El repertorio anecdótico de la fama americana del padre Feijoo en su tiempo se hace interminable y, en parte, ha quedado ya esbozado. ${ }^{10}$ Se cuenta que en cierta ocasión, al regresar de América el conde de las Torres, desembarcó en La Coruña y antes de dirigirse a Madrid hizo un largo rodeo - difícil por lo áspero del camino- hasta llegar a Oviedo, sólo por el gusto de saludar a Feijoo, cuya fama le seduce.

Todavía es más digna de subrayarse esta observación: el elogio y la fama se lo tributan de consuno, además de las gentes con él identificadas, también los militantes del campo opuesto. Y no sólo por esa «mucha porción de fama, gusto y conveniencia» que Diego Torres Villarroel considera como gozosa compensación a los ataques de adversarios o rivales, sino por el elogio rotundo y directo que brota a veces de los escritores de significación opuesta. Un escolástico de pura cepa, el P. Cristóbal Coriche, dominico, se refiere en la Oración vindicativa del honor de las letras, en 1763, al «tan docto cuanto imparcial y desapasionado, muy ilustre Feijoo, a quien los americanos debemos eterno agradecimiento". Y lo mismo el hábil polemista $\mathrm{P}$. Vallarta, antítesis de Feijoo, a cuya autoridad apela algunas veces; o el cubano Francisco Ignacio Cigala, que en 1760 publicó una violenta carta contra Feijoo, quizá por sentir herida

9. Francisco J. Eugenio de Santa Cruz y Espejo: El nuevo Luciano de Quito, ed. Quito, 1943.

10. Noticias de estos «elogios» y «congratulaciones" escritos por plumas americanas nos son proporcionadas en el interesante trabajo de Agustín Millares Carlo mencionado en la nota 2. 
su vanidad por el silencio de nuestro fraile, pero que por contraste ensalzaba la poderosa capacidad persuasiva del mismo.

Y así, alabado o discutido, promotor de una renovación de los modos del pensar en todo el mundo de habla española, este benedictino gallego (ni original en exceso, ni con pretensiones de genialidad) se aseguró un merecido renombre. Demoledor de errores comunes, animador de estudios nuevos, escritor de pluma leve, no amó la novedad a la ligera. Discutido en su tiempo, se anticipó a su tiempo. Por eso fue un promotor.

El creó un ambiente y preparó la circunstancia de los demás: tal es el ámbito de su influencia. Esa circunstancia abarca todas las direcciones de la rosa de los vientos de la Ilustración entre las gentes de América. Hace poco más de un año me tocó escuchar en la Universidad de Concepción, Chile, al historiador y ensayista norteamericano H. S. Commager la sorprendente afirmación de que la Ilustración europea había sido una pura comedia, porque Europa no logró con aquel movimiento de minorías intelectuales y déspotas ilustrados una auténtica liberación. ${ }^{11}$ Pero el P. Feijoo y el eco de su obra en América, he escrito yo en otra parte, ${ }^{12}$

«se bastan por sí solos para poner de relieve el impacto liberador de un pensamiento que no se contenta nunca, como ocurre con el pensamiento europeo, y que, gracias a esta tesonera, continua reelaboración, ha ido conquistando para el hombre de todos los continentes sus mejores posibilidades en el dominio de la Naturaleza y de la exaltación del espíritu».

El más grande polígrafo americano coetáneo de Feijoo, don Juan Peralta y Barnuevo, no tuvo reparo en exaltar la fama de nuestro fraile en unos versos de la Lima defendida, cuando todavía sólo habían salido a la luz pública los tres primeros tomos del Teatro Crítico:

Cuanto las ciencias tienen más brillante,

y la elocuencia da más elevado,

todos verán que cuando a España nace

si de él no se deriva, en él renace...

Y termina así el elogio:

Parecerá que del ingenio humano,

si se eligiera, él fuera el soberano.

11. H. S. Commager: Los Estados Unidos de América y la Ilustración, conferencia lelda en la Universidad de Concepción, Chile, el 21 de enero de 1963.

12. V. Palacio Atard: «Lo español y lo europeo en América», Cuadernos Hispanoamericanos, número 174, Madrid, junio 1964. 
Esta soberanía de la inteligencia, proclamada por el Talento Mayor de América, empareja dos nombres señeros en la historia de la cultura americana del siglo XviII. Y me complace record ${ }^{n r}$ en esta jornada el nombre del sabio peruano Peralta Barnuevo, porque en este mismo año de 1964 se ha cumplido el tercer centenario de su nacimiento.

Si el P. Feijoo significa que la ilustración europea es algo más que una comedia, la alineación paralela de Feijoo y de Peralta Barnuevo resulta quizás un simbólico emparejamiento hacia el futuro del común destino de estas culturas, indisolublemente hermanadas, de América y Europa. 